\title{
Targeting of PI3K/AKT signaling and DNA damage response in acute myeloid leukemia: a novel therapeutic strategy to boost chemotherapy response and overcome resistance
}

\author{
Montserrat Estruch ${ }^{1,2, \#}$, Camilla Vittori ${ }^{1,2, \#}$, Teresa Muñoz Montesinos ${ }^{1,2, \#}$, Kristian Reckzeh $^{1,2,3}$, Kim $^{2}$ \\ Theilgaard-Mönch ${ }^{1,2,3,4}$ \\ ${ }^{1}$ The Finsen Laboratory, Rigshospitalet/National University Hospital, Faculty of Health and Medical Sciences, University of \\ Copenhagen, Copenhagen DK-2200, Denmark. \\ ${ }^{2}$ Biotech Research and Innovation Centre, Faculty of Health and Medical Sciences, University of Copenhagen, Copenhagen DK- \\ 2200, Denmark. \\ ${ }^{3}$ Novo Nordisk Foundation Centre for Stem Cell Biology, DanStem, Faculty of Health and Medical Sciences, University of \\ Copenhagen, Copenhagen DK-2200, Denmark. \\ ${ }^{4}$ Department of Hematology, Rigshospitalet/National University Hospital, University of Copenhagen, Copenhagen DK-2200, \\ Denmark. \\ \#Authors contributed equally. \\ Correspondence to: Assoc. Prof. Kim Theilgaard-Mönch, MD, DMSc, Senior Consultant \& Research Group Leader, Department \\ of Hematology and The Finsen Laboratory, Rigshospitalet/National University Hospital and Biotech Research and Innovation \\ Center, University of Copenhagen, Ole Maaløes Vej 5, Copenhagen DK-2200, Denmark. E-mail: kim.theilgaard@bric.ku.dk; \\ kim.theilgaard-moench@regionh.dk
}

How to cite this article: Estruch M, Vittori C, Montesinos TM, Reckzeh K, Theilgaard-Mönch K. Targeting of PI3K/AKT signaling and DNA damage response in acute myeloid leukemia: a novel therapeutic strategy to boost chemotherapy response and overcome resistance. Cancer Drug Resist 2021;4:984-95. https://dx.doi.org/10.20517/cdr.2021.76

Received: 3 Aug 2021 First Decision: 7 Sep 2021 Revised: 19 Oct 2021 Accepted: 28 Oct 2021 Published: 10 Nov 2021

Academic Editor: Godefridus J. Peters Copy Editor: Yue-Yue Zhang Production Editor: Yue-Yue Zhang

\begin{abstract}
Resistance of cancer patients to DNA damaging radiation therapy and chemotherapy remains a major problem in the clinic. The current review discusses the molecular mechanisms of therapy resistance in acute myeloid leukemia (AML) conferred by cooperative chemotherapy-induced DNA damage response (DDR) and mutational activation of PI3K/AKT signaling. In addition, strategies to overcome resistance are discussed, with particular focus on studies underpinning the vast potential of therapies combining standard chemotherapy AML regimens with small molecule inhibitors targeting key regulatory hubs at the interface of DDR and oncogenic signaling pathways.
\end{abstract}


Keywords: DNA damage response, PI3K/AKT, chemotherapy, resistance, AML

\section{INTRODUCTION}

Resistance to conventional chemo- and radiotherapy is a mainstay of many cancer entities and a major obstacle in the clinic. Thus, understanding the molecular mechanisms of resistance in cancer patients is essential to define relevant druggable targets for therapeutic interventions and overcome therapy resistance.

Acute myeloid leukemia (AML) patients exhibit a dismal overall survival (OS) rate (five-year OS 25\%) due to primary resistance or relapse when treated with current standard AML chemotherapy regimen ${ }^{[1,2]}$. Survival remains particularly poor for elderly/unfit and relapsed/refractory (R/R) AML patients, who rarely survive beyond two years ${ }^{[1-3]}$.

AML emerges through sequential acquisition of genetic aberrations comprising a few drivers that partially promote abnormal activity of DNA damage response (DDR) and "oncogenic" signaling pathways, which together confer DNA repair, survival, proliferation, and ultimately therapy resistance toward current AML therapies $^{[2,4-8]}$. Thus, inhibition of drug resistance conferred by aberrant mutational activation of DDR and signaling pathways holds great potential to improve therapy response and OS of AML patients.

The current review deals with chemotherapy resistance in AML with particular focus on studies highlighting the potential of targeting DDR and phosphoinositide 3-kinase (PI3K)/protein kinase B (AKT) signaling pathways to overcome resistance in AML patients. For detailed information on therapeutic strategies targeting DDR and PI3K/AKT signaling pathways in other types of cancers, we refer to recent comprehensive reviews ${ }^{[9-21]}$.

\section{AML THERAPY}

Standard curative treatment of younger/fit AML patients ( $<65-75$ years) consists of intensive induction chemotherapy encompassing an antimetabolite (i.e., cytarabine) and a DNA damaging anthracycline (i.e., daunorubicin, doxorubicin, idarubicin, etc.) (in the following, cytarabine/anthracycline regimens are referred to as standard AML chemotherapy ${ }^{[1,2,22]}$. Following induction therapy, AML patients will proceed with consolidation therapy, comprising additional cycles of intensive chemotherapy or allogeneic stem cell transplantation, dependent on the individual AML patient's age, fitness, and genetic risk stratification ${ }^{[1,2]}$. Currently, only $40 \%$ of younger and fit AML patients are long-term survivors (i.e., five-year OS 40\%), as the majority relapse or exhibit primary resistance $(\mathrm{R} / \mathrm{R})$ toward current intensive therapeutic regimen $\mathrm{s}^{[1,2]}$. Of the remaining elderly/unfit ( $>75$ years) AML patients, who are not eligible for intensive standard AML chemotherapy, the vast majority do not survive two years $(<10 \%)$ due to limited clinical response to current non-curative standard regimens. These include best supportive care with or without hydroxurea, low-dose cytarabine (LDAC, CR/CRi 11\%-19\%, median OS < 6 months), and hypomethylating agents (HMAs, namely azacitidne/decitabine, CR/CRi 27\%, median OS 10.5 months), which also cause some degree of DNA damage ${ }^{[1,2,23]}$. More recent studies have highlighted the substantial therapeutic potential of the antiapoptotic BCL2 inhibitor venetoclax in combination with current standard AML regimens. More specifically, a seminal phase III trial combining azacytidine with venetoclax demonstrated significant improvement of response rates and survival of elderly/unfit AML patients as compared to single treatment with azacytidine alone (AZA/VEN vs. single AZA: CR/CRi 66.4\% vs. 28.3\%, median OS 14.7 vs. 9.6 months) ${ }^{[24]}$. Consistently, preliminary studies combining the hypomethylating agent decitabine (DEC) or azacytidine with venetoclax for R/R AML patients have demonstrated improved response rates (DEC/VEN or AZA/VEN, CR/CRi/MLFS 64\%) and survival rates (DEC/VEN or AZA/VEN, one-year OS 53\%, median 
OS not reached) as compared to single treatment with azacytidine or decitabine (CR/CRi 16\%, median OS 6.7 months) and similar response rates when compared to treatment with conventional intensive AML salvage chemotherapy (FLAG-IDA, CR/CRi 52\%, median OS 10 months) (25-27]. $^{[2}$.

\section{RATIONALE FOR THERAPEUTIC TARGETING OF DDR IN AML}

Many current cancer therapies cause replicative stress, leading to DNA damage. The latter launches a DDR [Figure 1], which in respect of outcome results in either survival or apoptosis depending on whether the level of cytotoxicity can overcome the capacity of cancer cells to repair DNA ${ }^{[8,10,11,17,19,28]}$. Hence, twisting the balance of therapy-induced DDR from survival toward apoptosis by inhibiting key regulators of the DDR, represents an attractive strategy to enhance sensitivity and overcome therapy resistance in cancer patient $^{[8,10,11]}$. Consistently, recent studies have highlighted the therapeutic potential of DDR inhibitors for the treatment of solid cancers and $\mathrm{AML}^{[29-34]}$.

Current AML standard therapies include cytarabine, anthracyclines, and HMAs such as azacytidine and decitabine. Cytarabine induces stalled replication forks leading to DDR activation promoting survival via the DDR master regulator ATR serine/threonine and its downstream substrates such as check point kinase 1 (CHK1) and WEE1 G2 checkpoint kinase (WEE1). Consistently, combinations of cytarabine and ATR inhibitors have demonstrated combinatorial therapeutic effect in some but not all studies on $\mathrm{AML}^{[35,36]}$.

Anthracyclines and to some extent HMA induce DNA double-strand breaks (DSB), leading to DDR activation and repair of DSB by homologous recombination (HR) and non-homologous end-joining (NHEJ), respectively ${ }^{[22,37]}$. HR and NHEJ are tightly orchestrated by the DDR master regulators ataxia telangiectasia mutated (ATM) and DNA-dependent protein kinase, catalytic subunit (DNA-PK), respectively, which through various DDR downstream substrates promote: (1) delay or block of cell cycle progression; (2) repair of DNA; or (3) TP53-mediated apoptosis if DNA is irreversibly damaged ${ }^{[8,1,38]}$. Hence, given the high rate of relapse and primary resistance of AML patients, there is a compelling rationale to combine DNA damaging standard AML chemotherapy and HMAs, with inhibitors of the DDR master regulators ATR, ATM, DNA-PK, and their DDR downstream substrates, to boost therapeutic efficacy and overcome therapy resistance.

\section{RATIONALE FOR THERAPEUTIC TARGETING OF PI3KIAKT SIGNALING}

Mutational activation of the PI3K/AKT signaling pathway is a common theme in cancer and is generally associated with a poor response to DNA damaging cancer therapies ${ }^{[12,13,15,21]}$.

Recent studies, mapping the genomic landscape in large AML cohorts, have identified mutations in more than $60 \%$ of AML patients, which directly or through intermediaries confer aberrant "oncogenic" activation of the PI3K/AKT signaling pathway [Table 1]. The latter include mutations of receptor tyrosine kinases [KIT proto-oncogene-receptor tyrosine kinase (KIT) and fms related receptor tyrosine kinase 3 (FLT3)], intracellular kinases [e.g., Janus kinase 2 (JAK2)], ASXL transcriptional regulator 1 (ASXL1), and GTPases [e.g., the neuroblastoma RAS viral oncogene homolog (NRAS) Kirsten rat sarcoma viral oncogene homolog (KRAS)], which are all frequently associated with a poor response to standard AML chemotherapy ${ }^{[5,40-49]}$.

Upon activation, PI3Ks and their second messenger phosphatidylinositol 3-phosphate promote phosphoinositide-dependent protein kinase-1 (PDPK1)- and mTOR complex 2 (mTORC2)-dependent phosphorylation of AKT at its T308 and S473 residues, respectively ${ }^{[20,50]}$. AKT itself activates numerous downstream targets including mTOR complex 1 (mTORC1), glycogen synthase kinase 3 (GSK3), and forkhead box proteins (FOXO). Together, PI3K/AKT downstream signaling directs: (1) proliferation; (2) 
Table 1. Frequency of mutations associated with PI3K/AKT activation in AML patients

\begin{tabular}{lll}
\hline Mutation & $\begin{array}{l}\text { Frequency (\%) } \\
\text { (mean age 60 years) }^{[5]}\end{array}$ & $\begin{array}{l}\text { Frequency (\%) } \\
\text { (mean age 77 years) }^{[39]}\end{array}$ \\
\hline KIT & 6 & $<3$ \\
FLT3-ITD/FLT3-TKD & 32 & 14 \\
NRAS/KRAS & 23 & 23 \\
JAK2 & $<0$ & 5 \\
ASXL1 & 6 & 10.5 \\
PTEN & $<0$ & $<2$ \\
\hline
\end{tabular}

PI3K: Phosphoinositide 3-kinase; AKT: protein kinase B; KIT: KIT proto-oncogene-receptor tyrosine kinase; FLT3: receptor tyrosine kinase 3; NRAS: neuroblastoma RAS viral oncogene homolog; KRAS: Kirsten rat sarcoma viral oncogene homolog; JAK2: Janus kinase 2; ASXL1: ASXL transcriptional regulator 1; PTEN: phosphatase and tensin homolog.

survival; (3) glucose metabolism; and (4) DNA repair ${ }^{[13,21,51,52]}$. Notably, PI3K/AKT exerts these activities partially through: (1) activation of MDM2-promoted TP53 degradation; (2) regulation of DDR molecule activities (CHK1 and BRCA1); and (3) upregulation of the anti-apoptotic MCL1 and BCL2 proteins through the cyclic adenosine monophosphate response element-binding protein (CREBBP) ${ }^{[51-56]}$. Because PI3K/AKT-dependent MCL1 expression can promote resistance to the recently approved BCL2 inhibitor venetoclax in patients with AML, simultaneous targeting of anti-apoptotic proteins such as MCL1, BCL2, or BCL2L1 (BCL-xL) and PI3K/AKT signaling might cooperatively boost apoptotic activity in AML cells. Indeed, this is corroborated by preclinical PDX trials of solid cancers and AML, highlighting the therapeutic benefit of PI3K/AKT inhibitors in combination with the BCL2 inhibitor venetoclax ${ }^{[57-59]}$. Since the majority of patients with AML will either not respond or in time develop resistance to venetoclax/azacytidine treatment ${ }^{[24]}$, there is a strong reason to explore the therapeutic efficacy of combination therapies including venetoclax and PI3K/AKT inhibitors alone or in combination with standard AML chemotherapy/HMAs.

In conclusion, the frequent mutational activation of PI3K/AKT signaling in AML patients, as well as its prominent role in therapy resistance, provides a rationale for targeted inhibition of PI3K/AKT signaling to enhance the efficacy of standard AML therapies and ultimately overcome therapy resistance.

\section{CROSSTALK BETWEEN DDR AND PI3KIAKT PATHWAYS}

There is compelling evidence of crosstalk activation and regulation between DDR and "oncogenic" signaling pathways including the PI3K/AKT signaling pathway [Figure 2] ${ }^{[60,61]}$. Studies have shown that AKT is directly phosphorylated (i.e., activated) by the DDR master regulators DNA-PK and ATM upon therapeutic DNA damage ${ }^{[21,60,62]}$. The latter marks the PI3K/AKT axis as a key regulatory hub, which enhances DNA repair and survival in response to DNA-PK or ATM cross-activation, through collateral regulation of DNA repair and inhibition of TP53-dependent apoptosis ${ }^{[21,53]}$. Consistently, targeted inhibition of PI3K/AKT signaling can confer replicative stress and cell death of cancer cells, underpinning its role in collateral enhancement of the DDR-mediated resistance to DNA damaging therapies ${ }^{[18,63]}$. Overall, these findings highlight the potential of therapies combining DDR and/or PI3K/AKT inhibitors with conventional therapies conferring replicative stress and DNA damage.

\section{PRECLINICAL STUDIES OF DDR AND PI3KIAKT INHIBITOR COMBINATION THERAPIES}

Mutational activation of the PI3K/AKT signaling pathway in AML patients is associated with poor clinical outcome when treated with intensive AML chemotherapy regimens including cytarabine and anthracyclines. The latter is illustrated by a significantly higher relapse rate of $t(8 ; 21)$ and inv(16) AML 


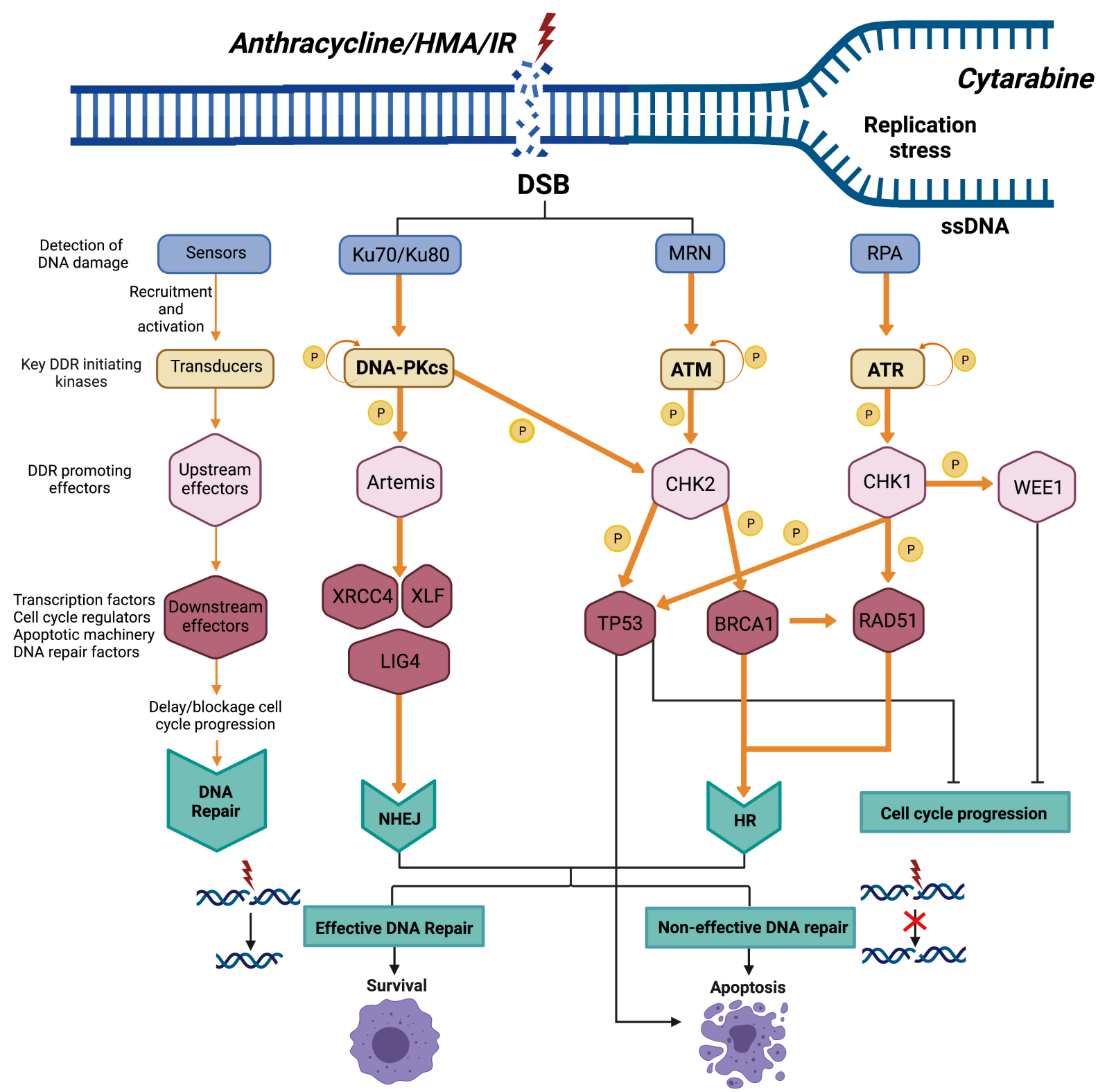

Figure 1. Schematic view of key DNA damage response pathways. Chemo- and radiotherapies (CT and IR) cause DNA damage, which launches a DNA damage response (DDR) to repair DNA and ensure survival of cancer cells. Current AML standard therapies include cytarabine, anthracyclines, or hypomethylating agents (HMAs) such as azacytidine and decitabine. Cytarabine induces stalled replication forks, leading to DDR activation, which promotes survival via the ATR/CHK1 axis and their downstream targets such as WEE1 in AML cells. Anthracyclines and to some extent HMAs such as azacitidine induce DSBs, leading to DDR activation and repair of DSB by $\mathrm{HR}$ and NHEJ, respectively. HR and NHEJ are tightly coordinated by the DDR-initiating master regulators ATM and DNA-PK, respectively, which through various DDR downstream substrates promote delay or block of cell cycle progression and repair of DNA, or TP53-mediated apoptosis if DNA is irreversibly damaged. Hence, in respect of outcome, chemotherapy-induced DNA damage and resultant DDR will confer either survival or apoptosis depending on whether the level of cytotoxicity can overcome the capacity of AML cells to repair DNA. IR: Irradiation/radiotherapy; CT: chemotherapy; DSB: double-strand break; P: phosphorylation; HR: homologous recombination; NHEJ: non-homologous end-joining; ATM: ataxia telangiectasia mutated; ATR: ATR serine/threonine kinase; CHK1: checkpoint kinase 1; CHK2: checkpoint kinase 2; DDR: DNA damage response; DNA-PK: DNA-dependent protein kinase catalytic subunit; DSB: double-strand breaks; HMAs: hypomethylating agents; MRN: Mre11, Rad50, and Nbs1 complex; TP53: tumor protein 53; BRCA1: BRCA1 DNA repair associated; WEE1: WEE1 G2 checkpoint kinase; XLF: XRCC4-like factor; XRCC4: X-ray repair cross complementing 4 . 


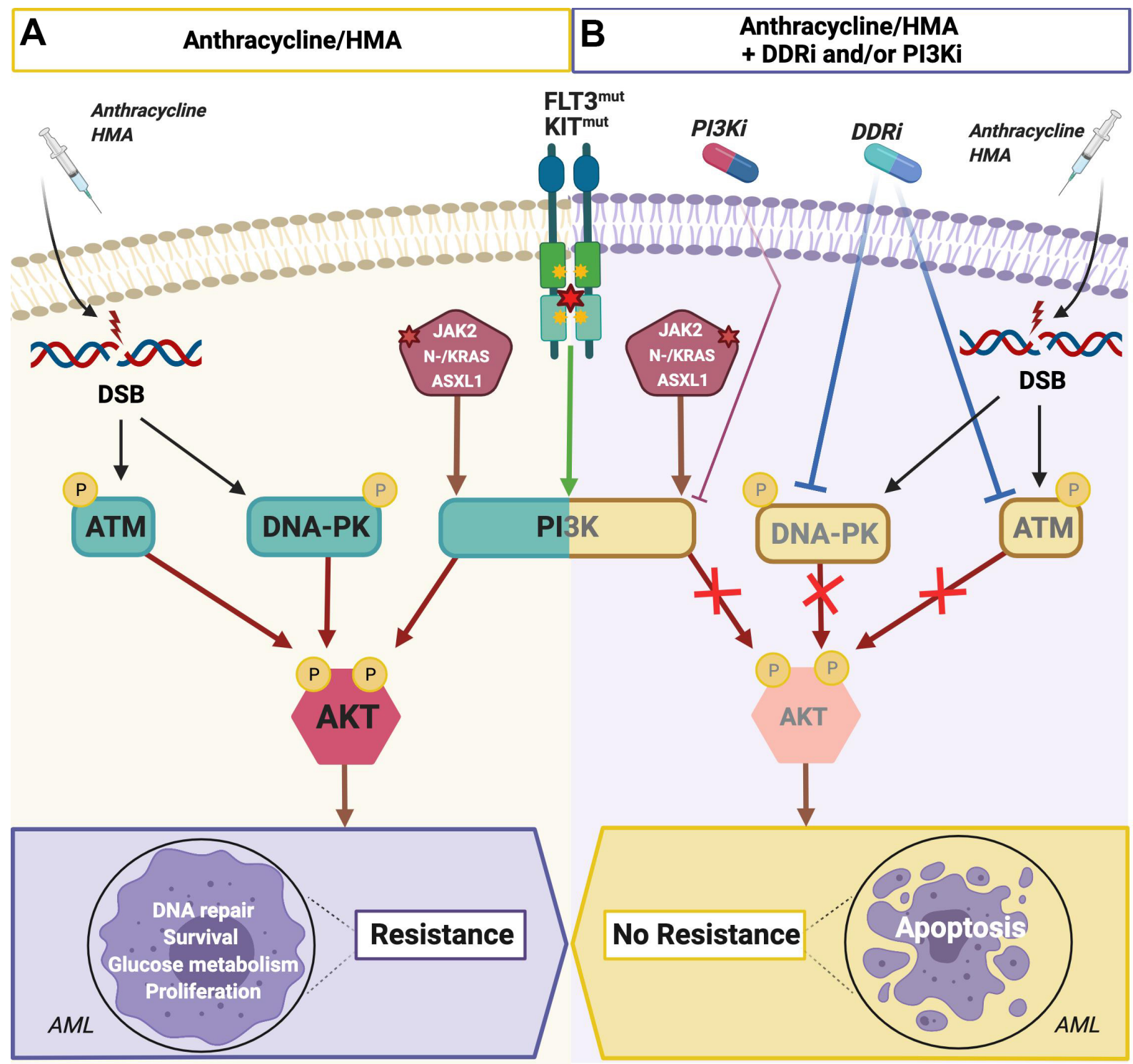

Figure 2. Rationale for combinatorial treatment of AML exhibiting mutational activation of PI3K/AKT signaling with inhibitors of DNA$\mathrm{PK}$ and/or PI3K/AKT and DSB-inducing AML chemotherapeutics (i.e., anthracyclines and HMAs). (A) AML cells harboring mutations in KIT, FLT3, JAK2, ASXL1, or NRAS/KRAS frequently exhibit constitutive "oncogenic" signaling including activation of the PI3K/AKT signaling pathway. Standard therapies for AML patients consist of: (1) cytarabine/anthracycline (dauno-, ida-, or doxorubicin) chemotherapy; or (2) HMAs such as azacytidine, which induce DSBs. Emerging therapy-induced DSBs launch a DDR partly via DNA-PKand/or ATM-dependent complementary enhancement of AKT downstream signaling, which promotes: (1) proliferation; (2) survival; (3) glucose metabolism; (4) DNA repair; and, ultimately (5) therapy resistance. (B) Simultaneous treatment with inhibitors of DDR or $\mathrm{PI3K} / \mathrm{AKT}$ signaling in combination with an anthracycline/HMA abrogates AKT downstream signaling and DNA repair, leading to increased DNA damage, apoptosis of AML cells, and ultimately better therapy response and clinical outcome. ATM: Ataxia telangiectasia mutated; ATR: ATR serine/threonine kinase; DDR: DNA damage response; DSBs: double-strand brakes; FLT3: fms related receptor tyrosine kinase 3; HMAs: hypomethylating agents; KIT: KIT proto-oncogene-receptor tyrosine kinase.

patients harboring gain-of-function KIT mutations $v s$. wild-type $\mathrm{KIT}^{[64-67]}$. In a recent study, Estruch et al. ${ }^{[68]}$ applied a genetically modified inv(16)/KIT ${ }^{\mathrm{D} 816 \mathrm{Y}}$ AML mouse model, mimicking AML patients with constitutive mutational KIT-dependent activation of the PI3K/AKT signaling pathway, to explore the therapeutic efficacy of standard AML chemotherapy in combination with DDR or PI3K/AKT inhibitors (i.e., DNA-PKi/NU7026 or pan-PI3Ki/BKM120). Treatment of inv(16)/KIT ${ }^{\mathrm{D} 16 \mathrm{Y}} \mathrm{AML}$ cells with 
chemotherapy markedly increased activation of AKT via DNA-PK-dependent phosphorylation. Complementary mechanistic experiments further demonstrated that chemotherapy in combination with either PI3K or DNA-PK inhibitors significantly decreased chemotherapy-induced activation of AKT signaling, leading to a significant increase of DNA damage and apoptosis of inv(16)/KIT ${ }^{\mathrm{D} 816 \mathrm{Y}}$ AML cells. Subsequent treatment, with a PI3K or a DNA-PK inhibitor in combination with standard AML chemotherapy, synergistically inhibited in vitro growth and survival of AML cells in clonogenic assays. Consistently, combination of standard AML chemotherapy and these inhibitors significantly improved overall survival of inv(16)/KIT ${ }^{\mathrm{D} 816 \mathrm{Y}}$ AML mice in preclinical trials compared to single treated or untreated mice. Intriguingly, treatment with the PI3K/AKT inhibitor alone abrogated PI3K signaling activity and exhibited some therapeutic activity in clonogenic assays and preclinical trials, whereas single treatment with the DNA-PK inhibitor elicited no therapeutic effect due to lack of DNA-PK activation in absence of chemotherapy-induced DNA damage.

In agreement with these findings, Ueno et al. ${ }^{[69]}$ recently demonstrated that simultaneous treatment with a FLT3 inhibitor (i.e., gilteritinib) and standard AML chemotherapy markedly enhanced chemotherapy response in FLT3-ITD mutant AML patient-derived xenografts.

Together, these preclinical studies suggest that DNA repair and survival of AML cells mediated by therapyinduced activation of a DDR and its collateral enhancement of constitutive mutational PI3K/AKT activation represents a key resistance mechanism in AML patients treated with DNA damaging therapies. Both studies further suggest that AML patients, who have a high mutational PI3K/AKT signaling activity potentially will benefit from combinatorial treatment with chemotherapy and DDR inhibitors and/or direct PI3K/AKT inhibitors or, alternatively, inhibitors of upstream PI3K/AKT activators such as KIT, FLT3, JAK2, ASXL1, and NRAS/KRAS. Since both standard AML induction chemotherapy and HMAs induce DSBs, which boost PI3K/AKT signaling in a DDR-dependent manner, the majority of AML patients treated with curative or non-curative therapeutic regimen will potentially benefit from complementary treatment with relevant small molecule inhibitors.

\section{CLINICAL STUDIES ADVOCATING THE THERAPEUTIC POTENTIAL OF DDR AND PI3KIAKT INHIBITOR COMBINATION THERAPIES}

Currently, DDR inhibitors remain to be approved for treatment of AML patients. However, several DDR inhibitors are currently being tested in clinical trials of solid cancers and AML, alone or in combination with DNA damaging and cytotoxic chemotherapy and radiation therapies, including CC-115 (DNAPKi/MTORi), nedisertib/M3814 (DNA-PKi), VE-821 (ATMi/ATRi), and VX-984 (DNA-PKi) ${ }^{[10,70]}$. Moreover, two recent studies depicted in Table 2 confirm that DDR inhibitors M6620/VX-970 (ATRi) and AZD1775 (Wee1i) enhance the efficacy of chemotherapies in patients with solid cancers ${ }^{[3,71]}$.

Even though several Phase I/II clinical trials have tested combinations of direct PI3K/AKT inhibitors and chemo- or radiotherapies in patients with solid cancers and AML, no inhibitors have thus far been approved for single or combinatorial treatment of AML patients ${ }^{[12,72]}$. However, recent studies have demonstrated that simultaneous treatment with FLT3 inhibitors, which potentially block mutational PI3K/AKT downstream signaling, significantly improved therapeutic efficacy of: (1) HMAs in elderly/unfit FLT3 mutant AML patients (azacytidine/gilteritinib); and (2) standard AML chemotherapy in younger FLT3 mutant AML patients (cytarabine/anthracycline/midostaurin or cytarabine/anthracycline/quizartinib) [Table 2] $]^{[73-75]}$. This potential therapeutic effect of combinatorial treatment is further supported by a seminal clinical trial demonstrating that simultaneous treatment of patients with $\mathrm{R} / \mathrm{R}$ chronic lymphatic leukemia with the PI $3 \mathrm{~K}$ inhibitor idelalisib and alkylating agent/antibody (i.e., bendamustine/rituximab), significantly improved the 
Table 2. Selected clinical trials combining direct/indirect PI3K inhibitors or DNA damage response inhibitors with chemotherapy or hypomethylating agents

\begin{tabular}{|c|c|c|c|c|c|c|c|}
\hline Compound & $\begin{array}{l}\text { Direct/indirect } \\
\text { PI3Ki }\end{array}$ & DDRi & $\begin{array}{l}\text { Study } \\
\text { design }\end{array}$ & Indication & Combination therapy & Clinical trial Ref. & Clinical outcome \\
\hline Quizartinib & FLT3 inhibitor & - & Phase I & de novo FLT3mut AML & $\mathrm{Q}+$ standard $\mathrm{CT}$ vs. standard CT & NCT $01390337^{[70]}$ & $\begin{array}{l}\text { ORR } 84 \% \text { ( } 16 / 19 \text { patients, } 14 \text { patients CRc + } 2 \\
\text { patients MLFS). No additional toxicity. }\end{array}$ \\
\hline Midostaurin & FLT3 inhibitor & - & Phase III & de novo FLT3mut AML & $\mathrm{M}+$ standard $\mathrm{CT}$ vs. standard $\mathrm{CT}$ & NCT00651261 ${ }^{[68]}$ & $\begin{array}{l}\text { OS } 74.7 \text { months (midostaurin) vs. } 25.6 \text { months } \\
\text { (placebo), } P=0.009 \text { ), median EFS } 8.2 \text { mo } \\
\text { (midostaurin) and } 3.0 \text { mo (placebo) } P=0.002 \text { ) }\end{array}$ \\
\hline Idelalisib & PI3K delta inhibitor & - & Phase III & $\begin{array}{l}\mathrm{R} / \mathrm{R} \text { chronic lymphocytic } \\
\text { leukaemia }\end{array}$ & $\begin{array}{l}\text { I + bendamustine/rituximab vs. } \\
\text { bendamustine/rituximab }\end{array}$ & NCT01569295 $5^{[71]}$ & $\begin{array}{l}\text { Median PFS } 20.8 \text { months (idelalisib) vs. } 11.1 \text { months } \\
\text { (placebo), } P<0.0001\end{array}$ \\
\hline Tucatinib & HER2 inhibitor & - & Phase II & $\begin{array}{l}\text { HER2-positive metastatic } \\
\text { breast cancer }\end{array}$ & $\begin{array}{l}\mathrm{T}+\text { trastuzumab/capecitabine vs. } \\
\text { trastuzumab/capecitabine }\end{array}$ & NCT02614794 ${ }^{[72]}$ & $\begin{array}{l}\text { 2-year OS at } 244.9 \% \text { (tucatinib) vs. } 26.6 \% \text { (placebo) } \\
P<0.005\end{array}$ \\
\hline $\begin{array}{l}\text { Berzosertib (VX- } \\
970, \text { M6620) }\end{array}$ & - & $\begin{array}{l}\text { ATR } \\
\text { inhibitor }\end{array}$ & Phase II & $\begin{array}{l}\text { Platinum-resistant high- } \\
\text { grade serous ovarian cancer }\end{array}$ & B + gemcitabine vs. gemcitabine & NCT02595892 ${ }^{[66]}$ & $\begin{array}{l}\text { Median PFS } 22.9 \text { weeks (berzosertib) vs. } 14.7 \text { weeks } \\
\text { (placebo), } P=0.044\end{array}$ \\
\hline AZD1775 & - & $\begin{array}{l}\text { Wee1 } \\
\text { inhibitor }\end{array}$ & Phase II & $\begin{array}{l}\text { TP53mut ovarian cancer, R/R } \\
\text { to first-line platinum-based } \\
\text { therapy }\end{array}$ & A + carboplatin & NCT01164995 $5^{[65]}$ & $\begin{array}{l}\text { Median PFS } 5.3 \text { months, OS } 12.6 \text { months. Clinical } \\
\text { proof that Wee1 inhibitor enhances carboplatin } \\
\text { efficacy in TP53-mutated tumors }\end{array}$ \\
\hline
\end{tabular}

ATR: ATR serine/threonine kinase; FLT3: rms telated teceptor tyrosine Kinase 3; HER2: human epidermal growth factor receptor 2; PI3K: phosphoinositide 3-kinase; R/R: relapsed/refractory; TP53: tumor protein P53; WEE1: WEE1 G2 checkpoint kinase; CRc: composite complete remission; EFS: event-free survival; ORR: overall response rate; MLFS: morphological leukemia-free state; OS: overall survival; PFS: progression-free survival.

median progression-free survival (PFS) as compared to treatment with alkylating agent/antibody alone (median PFS 20.8 months $v s .11 .1$ months, $P<0.0001$ ) [Table 2] ${ }^{[76]}$. Consistently, women with HER2-positive metastatic breast cancer markedly improved survival in response to triple treatment with a HER2 small molecule inhibitor (tucatinib), an anti-HER-antibody inhibiting ligand binding to HER (trastuzumab), and an antimetabolite (capecitabine) as compared to dual treatment with antibody/antimetabolite (two-year OS $44.9 \%$ vs. $26.6 \%, P=0.005$ ) [Table 2] ${ }^{[77]}$.

In conclusion, clinical trials highlight the therapeutic potential of DDR and PI3K/AKT inhibitor combination therapies and advocate for future AML trials investigating the efficacy of dual or triple combination therapies including DDR and/or PI3K inhibitors in combination with either chemotherapy or HMAs.

\section{PERSPECTIVES AND CHALLENGES OF DDR AND PI3KJAKT INHIBITOR COMBINATION THERAPIES}

Conceptually, cancer poly-therapies should combine drugs which: (1) exhibit additive or synergistic therapeutic activity; (2) target distinct cancer vulnerabilities to circumvent the development of resistance; and (3) can be administered at active therapeutic doses without surpassing clinically manageable levels of toxicity. Hence, the hallmark of cancer therapies combining novel drugs with standard therapies relates to whether their higher therapeutic efficacy outweighs the increase of toxicity and ultimately leads to a significant clinical benefit. The latter is particularly relevant in AML, considering the substantial 
toxicity of standard AML induction chemotherapies in younger AML patients as well as HMAs in elderly/unfit AML patients. Thus, the balance of benefit and toxicity is key to the design of clinical trials combining DDR and/or PI3K/AKT inhibitors with current AML therapies in terms of drug doses, duration of drug administration during treatment cycles, concomitant $v s$. sequential drug administration, and finally the length of treatment cycles. In this respect, recent experimental and clinical studies underscore that inhibitors of DDR and PI3K/AKT signaling pathways including FLT3 inhibitors should be administered simultaneously rather than sequentially with chemotherapy/HMAs to potentiate rather than complement therapeutic efficacy, as is the case with AML treatment regimens and ongoing trials combining standard AML chemotherapy with sequential inhibitor administration ${ }^{[7,75]}$. Although simultaneous treatment of AML patients with chemotherapy/HMAs and complementary drugs frequently comes with enhanced toxicity, primarily in the form of prolonged cytopenia and associated neutropenic infections, recent AML studies have demonstrated manageable toxicity and overall clinical benefit of standard AML therapies in combination with simultaneous administration of novel drugs ${ }^{[24,78-80]}$. However, future clinical trials are needed to define the optimal drug dosages for combination therapies encompassing a backbone of standard AML chemotherapy or HMAs and inhibitors of DDR and/or PI3K/AKT signaling pathways. Ideally, such clinical trials should be accompanied by exploratory biomarker analyses for guided treatment of responders and prevention of overtreatment of non-responders. Such biomarker assessment should include NGS-based genomics and complementary functional analyses such as drug screening and phosphoproteomics to predict AML patients responding to specific inhibitors of DDR and PI3K/AKT signaling pathways alone or in combination with chemotherapy/HMAs.

\section{CONCLUSION}

Oncogenic DDR and PI3K/AKT signaling activity is a common theme in various cancers, including AML, and is frequently associated with therapy resistance and poor clinical outcome. Hence, therapeutic targeting of DDR and PI3K/AKT signaling pathways alone or in combination with current standard AML chemotherapy and HMAs stands out as a potential strategy to overcome resistance and improve clinical outcome of AML patients. In a broader perspective, current findings highlight the vast potential of combining conventional DNA-damaging therapies with inhibition of signaling molecules at the interface of DDR and oncogenic signaling pathways to overcome therapy resistance and improve clinical outcome in patients with AML as well as other cancer entities.

\section{DECLARATIONS}

\section{Authors' contributions}

Conceptualized and wrote the review: Estruch M, Vittori C, Montesinos TM, Reckzeh K, Theilgaard-Mönch K

\section{Availability of data and materials}

All data and materials included in this review are available online.

\section{Financial support and sponsorship}

This work was supported by a grant from the Danish Cancer Society to ME (R167-A10932-17-S2). Theilgaard-Mönch K is supported by a clinical research fellowship and a center grant from the Novo Nordisk Foundation (grant no. 100191, Novo Nordisk Foundation Center for Stem Cell Biology, DanStem; grant no. NNF17CC0027852, KTM) and by grants from the Danish Council for Strategic Research (grant no. 133100153), the Danish Cancer Society (grant no. R72-A4572-13-S2, KTM), Børnecancerfonden (20160255), and Læge Sofus Carl Emil Friis og Hustru Olga Doris Friis Foundation (Theilgaard-Mönch K), and Tømrermester Jørgen Holm og Hustru Elisa, Brødrene Hartmans Fond, F. Hansen’s Mindelegat (Theilgaard-Mönch K). 


\section{Conflicts of interest}

All authors declared that there are no conflicts of interest.

\section{Ethical approval and consent to participate}

This review has been written in agreement with governmental ethical rules.

\section{Consent for publication}

Not applicable.

\section{Copyright}

(C) The Author(s) 2021.

\section{REFERENCES}

1. Döhner H, Weisdorf DJ, Bloomfield CD. Acute myeloid leukemia. N Engl J Med 2015;373:1136-52. DOI PubMed

2. Döhner H, Estey E, Grimwade D, et al. Diagnosis and management of AML in adults: 2017 ELN recommendations from an international expert panel. Blood 2017;129:424-47. DOI PubMed PMC

3. Dombret H, Gardin C. An update of current treatments for adult acute myeloid leukemia. Blood 2016;127:53-61. DOI PubMed PMC

4. Theilgaard-Mönch K, Boultwood J, Ferrari S, et al. Gene expression profiling in MDS and AML: potential and future avenues. Leukemia 2011;25:909-20. DOI PubMed

5. Papaemmanuil E, Gerstung M, Bullinger L, et al. Genomic classification and prognosis in acute myeloid leukemia. $N$ Engl $J$ Med 2016;374:2209-21. DOI PubMed PMC

6. Park S, Chapuis N, Tamburini J, et al. Role of the PI3K/AKT and mTOR signaling pathways in acute myeloid leukemia. Haematologica 2010;95:819-28. DOI PubMed PMC

7. Frelin C, Imbert V, Griessinger E, et al. Targeting NF-kappaB activation via pharmacologic inhibition of IKK2-induced apoptosis of human acute myeloid leukemia cells. Blood 2005;105:804-11. DOI PubMed

8. Bouwman P, Jonkers J. The effects of deregulated DNA damage signalling on cancer chemotherapy response and resistance. Nat Rev Cancer 2012;12:587-98. DOI PubMed

9. Blackford AN, Jackson SP. ATM, ATR, and DNA-PK: The trinity at the heart of the DNA damage response. Mol Cell 2017;66:80117. DOI PubMed

10. Pilié PG, Tang C, Mills GB, Yap TA. State-of-the-art strategies for targeting the DNA damage response in cancer. Nat Rev Clin Oncol 2019;16:81-104. DOI PubMed PMC

11. Dobbelstein M, Sørensen CS. Exploiting replicative stress to treat cancer. Nat Rev Drug Discov 2015;14:405-23. DOI PubMed

12. Darici S, Alkhaldi H, Horne G, Jørgensen HG, Marmiroli S, Huang X. Targeting PI3K/Akt/mTOR in AML: rationale and clinical evidence. J Clin Med 2020;9:2934. DOI PubMed PMC

13. Janku F, Yap TA, Meric-Bernstam F. Targeting the PI3K pathway in cancer: are we making headway? Nat Rev Clin Oncol 2018;15:273-91. DOI PubMed

14. Song M, Bode AM, Dong Z, Lee MH. AKT as a therapeutic target for cancer. Cancer Res 2019;79:1019-31. DOI PubMed

15. Nepstad I, Hatfield KJ, Grønningsæter IS, Reikvam H. The PI3K-Akt-mTOR signaling pathway in human acute myeloid leukemia (AML) cells. Int J Mol Sci 2020;21:2907. DOI PubMed PMC

16. Janku F. Phosphoinositide 3-kinase (PI3K) pathway inhibitors in solid tumors: from laboratory to patients. Cancer Treat Rev 2017;59:93-101. DOI PubMed

17. Reuvers TGA, Kanaar R, Nonnekens J. DNA damage-inducing anticancer therapies: from global to precision damage. Cancers (Basel) 2020;12:2098. DOI PubMed PMC

18. Huang TT, Lampert EJ, Coots C, Lee JM. Targeting the PI3K pathway and DNA damage response as a therapeutic strategy in ovarian cancer. Cancer Treat Rev 2020;86:102021. DOI PubMed PMC

19. Jackson SP, Helleday T. DNA REPAIR. Drugging DNA repair. Science 2016;352:1178-9. DOI PubMed

20. Fruman DA, Chiu H, Hopkins BD, Bagrodia S, Cantley LC, Abraham RT. The PI3K pathway in human disease. Cell 2017; 170:60535. DOI PubMed PMC

21. Liu Q, Turner KM, Alfred Yung WK, Chen K, Zhang W. Role of AKT signaling in DNA repair and clinical response to cancer therapy. Neuro Oncol 2014;16:1313-23. DOI PubMed PMC

22. Gewirtz D. A critical evaluation of the mechanisms of action proposed for the antitumor effects of the anthracycline antibiotics adriamycin and daunorubicin. Biochemical Pharmacology 1999;57:727-41. DOI PubMed

23. Dombret H, Seymour JF, Butrym A, et al. International phase 3 study of azacitidine vs conventional care regimens in older patients with newly diagnosed AML with $>30 \%$ blasts. Blood 2015;126:291-9. DOI PubMed PMC

24. DiNardo CD, Jonas BA, Pullarkat V, et al. Azacitidine and venetoclax in previously untreated acute myeloid leukemia. $N$ Engl $J$ Med 2020;383:617-29. DOI PubMed

25. Aldoss I, Yang D, Aribi A, et al. Efficacy of the combination of venetoclax and hypomethylating agents in relapsed/refractory acute myeloid leukemia. Haematologica 2018;103:e404-7. DOI PubMed PMC 
26. Pastore D, Specchia G, Carluccio P, et al. FLAG-IDA in the treatment of refractory/relapsed acute myeloid leukemia: single-center experience. Ann Hematol 2003;82:231-5. DOI PubMed

27. Stahl M, DeVeaux M, Montesinos P, et al. Hypomethylating agents in relapsed and refractory AML: outcomes and their predictors in a large international patient cohort. Blood Adv 2018;2:923-32. DOI PubMed PMC

28. Menolfi D, Zha S. ATM, ATR and DNA-PKcs kinases-the lessons from the mouse models: inhibition $\neq$ deletion. Cell Biosci 2020;10:8. DOI

29. Mateo J, Carreira S, Sandhu S, et al. DNA-Repair defects and olaparib in metastatic prostate cancer. N Engl J Med 2015;373:1697708. DOI PubMed PMC

30. Batey MA, Zhao Y, Kyle S, et al. Preclinical evaluation of a novel ATM inhibitor, KU59403, in vitro and in vivo in p53 functional and dysfunctional models of human cancer. Mol Cancer Ther 2013;12:959-67. DOI PubMed PMC

31. Foote KM, Blades K, Cronin A, et al. Discovery of 4-\{4-[(3R)-3-Methylmorpholin-4-yl]-6-[1-(methylsulfonyl)cyclopropyl]pyrimidin2-yl\}-1H-indole (AZ20): a potent and selective inhibitor of ATR protein kinase with monotherapy in vivo antitumor activity. $J$ Med Chem 2013;56:2125-38. DOI PubMed

32. Fok JHL, Ramos-Montoya A, Vazquez-Chantada M, et al. AZD7648 is a potent and selective DNA-PK inhibitor that enhances radiation, chemotherapy and olaparib activity. Nat Commun 2019;10:5065. DOI PubMed PMC

33. Leijen S, van Geel RM, Sonke GS, et al. Phase II study of WEE1 inhibitor AZD1775 plus carboplatin in patients with TP53-mutated ovarian cancer refractory or resistant to first-line therapy within 3 months. J Clin Oncol 2016;34:4354-61. DOI PubMed

34. Riches LC, Trinidad AG, Hughes G, et al. Pharmacology of the ATM inhibitor AZD0156: potentiation of irradiation and olaparib responses preclinically. Mol Cancer Ther 2020;19:13-25. DOI PubMed

35. Fordham SE, Blair HJ, Elstob CJ, et al. Inhibition of ATR acutely sensitizes acute myeloid leukemia cells to nucleoside analogs that target ribonucleotide reductase. Blood Adv 2018;2:1157-69. DOI PubMed PMC

36. Ma J, Li X, Su Y, et al. Mechanisms responsible for the synergistic antileukemic interactions between ATR inhibition and cytarabine in acute myeloid leukemia cells. Sci Rep 2017;7:41950. DOI PubMed PMC

37. Palii SS, Van Emburgh BO, Sankpal UT, Brown KD, Robertson KD. DNA methylation inhibitor 5-Aza-2'-deoxycytidine induces reversible genome-wide DNA damage that is distinctly influenced by DNA methyltransferases 1 and 3B. Mol Cell Biol 2008;28:75271. DOI PubMed PMC

38. Lukas J, Lukas C, Bartek J. More than just a focus: the chromatin response to DNA damage and its role in genome integrity maintenance. Nat Cell Biol 2011;13:1161-9. DOI PubMed

39. Colell MH, Dolnik A, Blätte TJ, et al. Molecular profiles in AML patients older than 70 years of age. Abstract PF213. Available from: https://library.ehaweb.org/eha/2018/stockholm/214704/montserrat.hoyos.colell.molecular.profiles.in.aml.patients.older.than.70.years.h tml? $\mathrm{f}=$ media $=1 *$ listing $=3 *$ browseby $=8$ [Last accessed on 4 Nov 2021].

40. Gerstung M, Papaemmanuil E, Martincorena I, et al. Precision oncology for acute myeloid leukemia using a knowledge bank approach. Nat Genet 2017;49:332-40. DOI PubMed PMC

41. Bullinger L, Döhner K, Döhner H. Genomics of acute myeloid leukemia diagnosis and pathways. J Clin Oncol 2017;35:934-46. DOI PubMed

42. Rapin N, Bagger FO, Jendholm J, et al. Comparing cancer vs normal gene expression profiles identifies new disease entities and common transcriptional programs in AML patients. Blood 2014;123:894-904. DOI PubMed

43. Xu Q, Simpson SE, Scialla TJ, Bagg A, Carroll M. Survival of acute myeloid leukemia cells requires PI3 kinase activation. Blood 2003;102:972-80. DOI PubMed

44. Fujino T, Goyama S, Sugiura Y, et al. Mutant ASXL1 induces age-related expansion of phenotypic hematopoietic stem cells through activation of Akt/mTOR pathway. Nat Commun 2021;12:1826. DOI PubMed PMC

45. Min YH, Eom JI, Cheong JW, et al. Constitutive phosphorylation of Akt/PKB protein in acute myeloid leukemia: its significance as a prognostic variable. Leukemia 2003;17:995-7. DOI PubMed

46. Pardee TS, Zuber J, Lowe SW. Flt3-ITD alters chemotherapy response in vitro and in vivo in a p53-dependent manner. Exp Hematol 2011;39:473-85.e4. DOI PubMed PMC

47. Dos Santos C, McDonald T, Ho YW, et al. The Src and c-Kit kinase inhibitor dasatinib enhances p53-mediated targeting of human acute myeloid leukemia stem cells by chemotherapeutic agents. Blood 2013;122:1900-13. DOI PubMed PMC

48. Gallay N, Dos Santos C, Cuzin L, et al. The level of AKT phosphorylation on threonine 308 but not on serine 473 is associated with high-risk cytogenetics and predicts poor overall survival in acute myeloid leukaemia. Leukemia 2009;23:1029-38. DOI

49. Chen P, Jin Q, Fu Q, et al. Induction of multidrug resistance of acute myeloid leukemia cells by cocultured stromal cells via upregulation of the PI3K/Akt signaling pathway. Oncol Res 2016;24:215-23. DOI PubMed PMC

50. Fedele CG, Ooms LM, Ho M, et al. Inositol polyphosphate 4-phosphatase II regulates PI3K/Akt signaling and is lost in human basallike breast cancers. Proc Natl Acad Sci U S A 2010;107:22231-6. DOI PubMed PMC

51. Badura M, Braunstein S, Zavadil J, Schneider RJ. DNA damage and eIF4G1 in breast cancer cells reprogram translation for survival and DNA repair mRNAs. Proc Natl Acad Sci U S A 2012;109:18767-72. DOI PubMed PMC

52. Musa F, Alard A, David-West G, Curtin JP, Blank SV, Schneider RJ. Dual mTORC1/2 inhibition as a novel strategy for the resensitization and treatment of platinum-resistant ovarian cancer. Mol Cancer Ther 2016;15:1557-67. DOI PubMed PMC

53. Li W, Peng X, Lang J, Xu C. Targeting mouse double minute 2: current concepts in DNA damage repair and therapeutic approaches in cancer. Front Pharmacol 2020;11:631. DOI PubMed PMC

54. Wang JM, Chao JR, Chen W, Kuo ML, Yen JJ, Yang-Yen HF. The antiapoptotic gene mcl-1 is up-regulated by the phosphatidylinositol 3-kinase/Akt signaling pathway through a transcription factor complex containing CREB. Mol Cell Biol 
1999;19:6195-206. DOI PubMed PMC

55. Pugazhenthi S, Nesterova A, Sable C, et al. Akt/protein kinase B up-regulates Bcl-2 expression through cAMP-response elementbinding protein. J Biol Chem 2000;275:10761-6. DOI PubMed

56. Tonic I, Yu WN, Park Y, Chen CC, Hay N. Akt activation emulates Chk1 inhibition and Bcl2 overexpression and abrogates G2 cell cycle checkpoint by inhibiting BRCA1 foci. J Biol Chem 2010;285:23790-8. DOI PubMed PMC

57. Pilling AB, Hwang C. Targeting prosurvival BCL2 signaling through Akt blockade sensitizes castration-resistant prostate cancer cells to enzalutamide. Prostate 2019;79:1347-59. DOI PubMed PMC

58. Rahmani M, Anderson A, Habibi JR, et al. The BH3-only protein Bim plays a critical role in leukemia cell death triggered by concomitant inhibition of the PI3K/Akt and MEK/ERK1/2 pathways. Blood 2009;114:4507-16. DOI PubMed PMC

59. Rahmani M, Nkwocha J, Hawkins E, et al. Cotargeting BCL-2 and PI3K induces BAX-dependent mitochondrial apoptosis in AML cells. Cancer Res 2018;78:3075-86. DOI PubMed PMC

60. Bozulic L, Surucu B, Hynx D, Hemmings BA. PKBalpha/Akt1 acts downstream of DNA-PK in the DNA double-strand break response and promotes survival. Mol Cell 2008;30:203-13. DOI PubMed

61. Park J, Feng J, Li Y, Hammarsten O, Brazil DP, Hemmings BA. DNA-dependent protein kinase-mediated phosphorylation of protein kinase B requires a specific recognition sequence in the C-terminal hydrophobic motif. J Biol Chem 2009;284:6169-74. DOI PubMed

62. Halaby MJ, Hibma JC, He J, Yang DQ. ATM protein kinase mediates full activation of Akt and regulates glucose transporter 4 translocation by insulin in muscle cells. Cell Signal 2008;20:1555-63. DOI PubMed

63. Lamm N, Rogers S, Cesare AJ. The mTOR pathway: implications for DNA replication. Prog Biophys Mol Biol 2019;147:17-25. DOI PubMed

64. Paschka P, Marcucci G, Ruppert AS, et al; Cancer and Leukemia Group B. Adverse prognostic significance of KIT mutations in adult acute myeloid leukemia with inv(16) and t(8;21): a Cancer and Leukemia Group B Study. J Clin Oncol 2006;24:3904-11. DOI PubMed

65. Yui S, Kurosawa S, Yamaguchi H, et al. D816 mutation of the KIT gene in core binding factor acute myeloid leukemia is associated with poorer prognosis than other KIT gene mutations. Ann Hematol 2017;96:1641-52. DOI PubMed

66. Park SH, Chi HS, Cho YU, Jang S, Park CJ. Effects of c-KIT mutations on expression of the RUNX1/RUNX1T1 fusion transcript in t(8;21)-positive acute myeloid leukemia patients. Leuk Res 2013;37:784-9. DOI PubMed

67. Schnittger S, Kohl TM, Haferlach T, et al. KIT-D816 mutations in AML1-ETO-positive AML are associated with impaired event-free and overall survival. Blood 2006;107:1791-9. DOI PubMed

68. Estruch M, Reckzeh K, Vittori C, et al. Targeted inhibition of cooperative mutation- and therapy-induced AKT activation in AML effectively enhances response to chemotherapy. Leukemia 2021;35:2030-42. DOI PubMed

69. Ueno Y, Mori M, Kamiyama Y, et al. Evaluation of gilteritinib in combination with chemotherapy in preclinical models of FLT3-ITD acute myeloid leukemia. Oncotarget 2019;10:2530-45. DOI PubMed PMC

70. Munster PN, Mahipal A, Nemunaitis JJ, et al. Phase I trial of a dual TOR kinase and DNA-PK inhibitor (CC-115) in advanced solid and hematologic cancers. J Clin Oncol 2016;34:2505. DOI

71. Konstantinopoulos PA, Cheng S, Wahner Hendrickson AE, et al. Berzosertib plus gemcitabine versus gemcitabine alone in platinumresistant high-grade serous ovarian cancer: a multicentre, open-label, randomised, phase 2 trial. Lancet Oncol 2020;21:957-68. DOI PubMed PMC

72. Ragon BK, Kantarjian H, Jabbour E, et al. Buparlisib, a PI3K inhibitor, demonstrates acceptable tolerability and preliminary activity in a phase I trial of patients with advanced leukemias. Am J Hematol 2017;92:7-11. DOI PubMed PMC

73. Stone RM, Larson RA, Döhner H. Midostaurin in FLT3-mutated acute myeloid leukemia. N Engl J Med 2017;377:1903. DOI PubMed

74. Wang ES, Montesinos P, Minden MD, et al. Phase 3, Multicenter, Open-label study of gilteritinib, gilteritinib plus azacitidine, or azacitidine alone in newly diagnosed FLT3 mutated (FLT3mut+) acute myeloid leukemia (AML) patients ineligible for intensive induction chemotherapy. 62nd ASH Annual Meeting and Exposition; 2020 Dec 5-8. Available from: https://ash.confex.com/ash/2020/webprogram/Paper137708.html [Last accessed on 1 Nov 2021].

75. Altman JK, Foran JM, Pratz KW, Trone D, Cortes JE, Tallman MS. Phase 1 study of quizartinib in combination with induction and consolidation chemotherapy in patients with newly diagnosed acute myeloid leukemia. Am J Hematol 2018;93:213-21. DOI PubMed PMC

76. Zelenetz AD, Barrientos JC, Brown JR, et al. Idelalisib or placebo in combination with bendamustine and rituximab in patients with relapsed or refractory chronic lymphocytic leukaemia: interim results from a phase 3, randomised, double-blind, placebo-controlled trial. Lancet Oncol 2017;18:297-311. DOI PubMed PMC

77. Murthy RK, Loi S, Okines A, et al. Tucatinib, trastuzumab, and capecitabine for HER2-positive metastatic breast cancer. $N$ Engl $J$ Med 2020;382:597-609. DOI PubMed

78. Castaigne S, Pautas C, Terré C, et al. Effect of gemtuzumab ozogamicin on survival of adult patients with de-novo acute myeloid leukaemia (ALFA-0701): a randomised, open-label, phase 3 study. Lancet 2012;379:1508-16. DOI PubMed

79. Stein EM, DiNardo CD, Fathi AT, et al. Ivosidenib or enasidenib combined with intensive chemotherapy in patients with newly diagnosed AML: a phase 1 study. Blood 2021;137:1792-803. DOI PubMed PMC

80. DiNardo CD, Stein AS, Stein EM, et al. Mutant isocitrate dehydrogenase 1 inhibitor ivosidenib in combination with azacitidine for newly diagnosed acute myeloid leukemia. J Clin Oncol 2021;39:57-65. DOI PubMed PMC 